\title{
The effects of the forward speed and air volume of an air-assisted sprayer on spray deposition in tendone trained vineyards
}

\author{
Simone Pascuzzi \\ Department of Agricultural and Environmental Science, Aldo Moro University of Bari, Italy
}

\begin{abstract}
This paper reports the results of spray application trials in a tendone trained vineyard in order to evaluate the influence of forward speed and air volume on the foliar deposition of plant protection products (PPPs), maintaining roughly constant the volume applied. The trials used an air-assisted sprayer with a centrifugal fan and $4+4$ adjustable fan-shaped diffusers, each with a nozzle-holder group. A full factorial experimental design was implemented, with three forward speeds and two airflow rates, organised with a randomised complete block design including three replicates. In order to consider the influence of canopy development, the tests (one spray application for each replicate of a mixture containing a water-soluble food dye as a tracer) were replicated during two phenological stages: i) the end of flowering; and ii) berry touch. Leaves were picked at random from the canopy after each spray treatment, and foliar PPP deposition was evaluated using a spectrophotometer. This analysis of foliar deposition showed that the airflow rates produced by the fan were unsuitable for the dense canopy typical of this type of vineyard. However, the special shape of the diffusers may make this sprayer effective if the main objective of pesticide applications in tendone trained table grape vineyards is to control bunch diseases.
\end{abstract}

\footnotetext{
Correspondence: Simone Pascuzzi, Department of Agricultural and Environmental Science (DiSAAT), Aldo Moro University of Bari, via Amendola 165/A, 70126 Bari, Italy.

Tel.Fax: +39.080 .5442214 .

E-mail: simone.pascuzzi@uniba.it
}

Key words: airflow rate, forward speed, sprayer, tendone training system, vineyard.

Funding: research developed within the MIUR project Improvement of Deposition Efficiency of Vineyard Sprayers, prot. 2001073192.

Acknowledgements: the author wishes to thank C. Gidiuli, V. Marzano and D. Sfregola of DiSAAT for their help and commitment in conducting the experimental tests.

Received for publication: 9 June 2013.

Accepted for publication: 19 November 2013.

CCCopyright S. Pascuzzi, 2013

Licensee PAGEPress, Italy

Journal of Agricultural Engineering 2013; XLIV:e18

doi:10.4081/jae.2013.e18

This article is distributed under the terms of the Creative Commons Attribution Noncommercial License (by-nc 3.0) which permits any noncommercial use, distribution, and reproduction in any medium, provided the original author(s) and source are credited.

\section{Introduction}

Apulia, southern Italy, is the country's leading region in the production of table grapes, with a cultivated area of over 32,000 hectares $(\mathrm{Ha})$ and production of approximately $6.5 \times 10^{8} \mathrm{~kg}$, accounting for $61 \%$ of total national production (ISTAT, 2012). The most common vine training system used by Apulian grape growers for table grapes is the pergola or tendone system.

The main characteristic of tendone trained vineyards is their canopy distribution on a continuous horizontal plane approximately 2 $\mathrm{m}$ above the ground level. Canopy thickness is not uniform, and is widely affected by the grape variety, agronomic practices, climatic conditions, pruning techniques, and covering systems. This canopy is supported by a trellis system consisting of a $2.10 \mathrm{~m}$ high post at each vine with two orthogonal steel wires attached $1.8 \mathrm{~m}$ above ground level, and a grid of steel wires approximately $0.20 \mathrm{~m}$ apart supporting the shoots. Vines have a 1.2-1.4 m high trunk, with two branches and two fruitbearing shoots per branch, aligned orthogonally or parallel on the grid. This grid creates an ideal boundary layer between an upper area exclusively for the canopy, and a lower area for the grape clusters distributed on all or part of the width of the inter-row, and directly exposed to the spray during application of plant protection products (PPPs).

In addition, table grape vineyards using a tendone training system also have a second horizontal grid of steel wires dividing the canopy in the upper area into two levels (double-grid tendone); the higher level supports the growing shoots and the lower level supports the fruitbearing shoots.

In these vineyards, only the lower side of the canopy is sprayed. The effectiveness of agrochemical treatments is greatly influenced by the spatial distribution of the canopy (in terms of height, thickness, leaf density, discontinuity along the rows) and grape clusters, and by the spray jet that must also reach the less-exposed foliage. For this reason, in order to improve the efficiency of PPP application, the sprayers must be calibrated according to the intended application, crop growth stage (Salyani and Serdynski, 1993; Cross et al., 2001a; Cross et al., 2001b; Wachowiak and Kierzek, 2009) and pesticide formulation (Balsari et al., 2007), and also according to the specific morphological and canopy pattern of the vineyard.

The sprayers generally used for pesticide treatments in Apulian tendone vineyards are conventional air-assisted sprayers equipped with arc-shaped spray boom and axial-flow fan, pneumatic sprayers fitted with air shear nozzles, and a centrifugal fan producing an air flow through fixed or adjustable diffusers along an arc of $180^{\circ}$. The conventional sprayers pose a number of problems when used in tendone vineyards because it is difficult to adjust airflow directions and nozzle orientation; on the other hand, it is possible to make only a few adjustments to the pneumatic spray diffusers (Guarella and Pascuzzi, 2000; Guarella and Pascuzzi, 2002).

In Apulian tendone vineyards, the interaction between the main parameters influencing the success of PPP application (forward speed, air flow rate, and application volume) could be the subject of specific 
and systematic research in the future, aimed at providing vine growers with precise guidelines.

Forward speed influences the quality of the spray deposit and the working capacity of the sprayers. In this respect, Cerruto's work on Sicilian tendone vineyards, using a sprayer with adjustable spraying modules, did not report any significant modifications of the mean foliar deposition for forward speeds in the range 1.05-1.58 $\mathrm{m} \mathrm{s}^{-1}$ (Cerruto et al., 2008). Furthermore, Pergher used a sprayer with an axial fan on hedgerow vineyards and reported that forward speeds higher than 2.5 $\mathrm{m} \mathrm{s}^{-1}$ might reduce spray penetration into the canopy and increase deposit variability (Pergher, 2006). Cerruto also studied the same type of vineyard using an air-assisted towed sprayer, and did not record significant modification of the mean foliar deposition for forward speeds in the range $0.9-2.8 \mathrm{~m} \mathrm{~s}^{-1}$, but obtained the best uniformity on the canopy by using an intermediate forward speed $\left(1.4 \mathrm{~m} \mathrm{~s}^{-1}\right)$ (Cerruto, 2007b).

Planas et al. reported that an increase in forward speed from $1.0 \mathrm{~m}$ $\mathrm{s}^{-1}$ to $1.7 \mathrm{~m} \mathrm{~s}^{-1}$ improved the foliar deposition in apple orchards but reduced the uniformity of deposition (Planas et al., 1998); Salyani and Withney obtained equivalent results in citrus trees, recording increased variability in the deposition on the crop with an increase in forward speed (Salyani and Withney, 1990).

It is known that the use of the airstream for orchard spraying is advantageous because it carries the droplets from the nozzle to the target, and creates a little turbulence within the canopy that helps penetration and gives a better coverage of the plant surface, including the undersides of leaves.

The setting of the correct air volume depends on the characteristics of the target plants (training system, tree size, canopy shape, foliage density, distance between the rows), the forward speed, and the typology of the fan (Balsari and Tamagnone, 1998).

Cerruto used the same sprayer in tendone vineyards, and did not record any significant modification of the mean foliar deposition when increasing the airflow rate from $1.81 \mathrm{~m}^{3} \mathrm{~s}^{-1}$ to $2.14 \mathrm{~m}^{3} \mathrm{~s}^{-1}$ (Cerruto et al., 2008). However, when Pergher used a standard air-assisted sprayer in a hedgerow vineyard, lower deposition levels were recorded on the foliage when the airflow rate was increased from $4.7 \mathrm{~m}^{3} \mathrm{~s}^{-1}$ to $10.6 \mathrm{~m}^{3}$ $\mathrm{s}^{-1}$ (Pergher and Gubiani, 1995; Pergher, 2006), and Cerruto also obtained similar results by raising the airflow rate from $3.9 \mathrm{~m}^{3} \mathrm{~s}^{-1}$ to 7.5 $\mathrm{m}^{3} \mathrm{~s}^{-1}$ (Cerruto, 2007a). Pezzi and Rondelli reported lower deposition on the foliage in a Casarsa vineyard when the airflow rate was increased from $4.2 \mathrm{~m}^{3} \mathrm{~s}^{-1}$ to $7.2 \mathrm{~m}^{3} \mathrm{~s}^{-1}$, although the increased airflow rate improved the uniformity of the spray coverage (Pezzi and Rondelli, 2000). On the other hand, when Cross et al. used axial fan sprayers on different-sized apple trees, they reported that an increase in the airflow rate from $4.1 \mathrm{~m}^{3} \mathrm{~s}^{-1}$ to $11.3 \mathrm{~m}^{3} \mathrm{~s}^{-1}$ did not affect the variability of deposits on leaf surface, but produced an increase in spray drift (Cross et al., 2003). Salyani and Farooq's work on citrus groves highlighted the significant effect of the airflow rate on spray penetration, obtaining comparable foliar deposition with lower and higher airflow rates in most canopy locations (Salyani and Farooq, 2003).

Vieri presented an instrumental procedure for evaluating the instantaneous force of the air-jet produced by the fan and diffusers. This equipment made it possible to measure the impulse and momentum of airflow in dynamic conditions, i.e. with the sprayer moving through the orchard (Vieri, 2003).

The aim of the current study was to evaluate the effects of the forward speed and airflow rate on foliar deposition in a typical Apulian tendone vineyard, using an innovative sprayer model compared to the standard air-assisted sprayers traditionally used by growers. The experimental plan was replicated at two different phenological stages in order to consider the development of the vegetation.

\section{Materials and methods}

\section{Experimental set-up}

Simulated treatments were carried out in a double-grid tendone trained vineyard (Italia grape variety) situated on a plain in Adelfia (Province of Bari, southern Italy). The vineyard had an anti-hail net, and the vines were approximately $2.24 \times 2.24 \mathrm{~m}$ apart, giving a density of 2000 plants per Ha.

Vineyard characteristics were those frequently adopted for the table grape tendone vineyards in the Province of Bari: vertical vine trunks with four fruit-bearing shoots aligned parallel to the transit direction of the machinery and supported by steel wires forming a first grid at a height of $1.86 \mathrm{~m}$ above ground level (Figure 1). The second horizontal wire grid was approximately $2.06 \mathrm{~m}$ above ground level.

The experimental plan was replicated in two different phenological stages: the end of flowering (code 69 of the Biologische Bundesanstalt, Bundessortenamt und Chemische Industrie scale, BBCH, June 17) and berry touch (code 79 of the BBCH scale, July15) (Eichhorn, 1984).

The trials involved a trailed Nobili OKTOPUS mini 40-600-MT (Italy) air-assisted sprayer with a $600 \mathrm{~L}$ tank (Figure 2), a more modern model than those traditionally used in Apulian tendone trained vineyards. Although it relied on a pressure-driven atomising mechanism, this machine had a centrifugal fan and spray-orienting diffusers like those typical of sprayers working with shear-air nozzles. This sprayer operated at $56.5 \mathrm{rad} \mathrm{s}^{-1}$ of the tractor power take-off and had $4+4$ adjustable fan-shaped diffusers, each with a nozzle-holder group fitted with an anti-drip device.

The tests were carried out using simultaneously only the four $(2+2)$ nozzles closer to the median plane of the machine, while the air produced by the fan was emitted through all the diffusers. The influence of the forward speed and the airflow rate on foliar deposition was evaluated using a full factorial experimental design considering three forward speeds $\left(v_{1}=0.67 \mathrm{~m} \mathrm{~s}^{-1} ; v_{2}=1.08 \mathrm{~m} \mathrm{~s}^{-1} ; v_{3}=1.58 \mathrm{~m} \mathrm{~s}^{-1}\right)$ and two airflow rates $\left(\mathrm{A}_{1}=1.68 \mathrm{~m}^{3} \mathrm{~s}^{-1} ; \mathrm{A}_{2}=2.73 \mathrm{~m}^{3} \mathrm{~s}^{-1}\right)$. Airflow rate $\mathrm{A}_{2}$ was the maximum delivered by the fan, while airflow rate $A_{1}$ was approximately $60 \%$ of $\mathrm{A}_{2}$, and was obtained by using the lowest fan gear and choking suction with a plastic stopper disc on the air intake (Figure 2).

The airflow rates were measured using a pipe (diameter $=0.8 \mathrm{~m}$ and length=10 m) fitted to the fan intake (ISO 9898:2000) (ISO, 2000; ENAMA, 1996). The air speed inside the pipe was measured using a

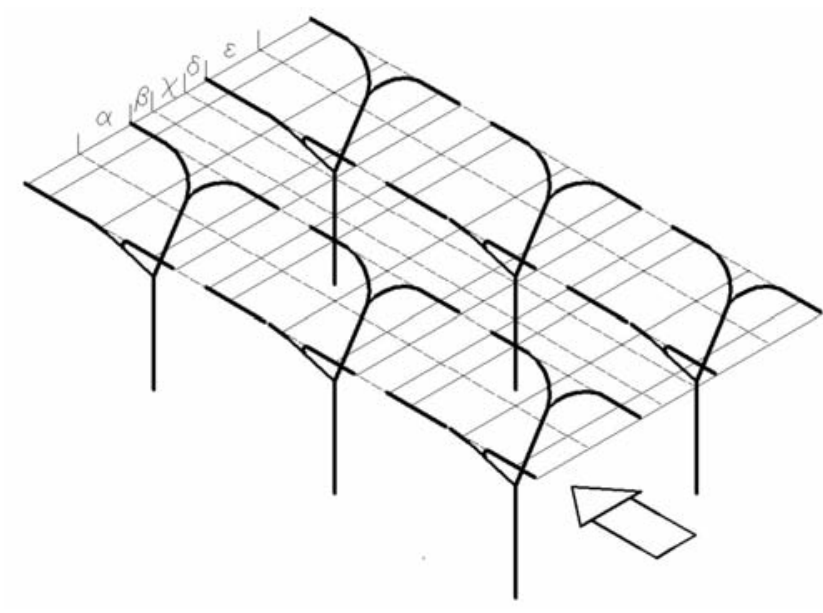

Figure 1. Tendone trained vineyard under study. The 4-aligned parallel bearing shoots arrangement. 
hot-wire anemometer (LSI model BS-V101) with the following technical characteristics: a measurement range of $0 \div 50 \mathrm{~m} \mathrm{~s}^{-1}$; precision of $\pm 0.04 \mathrm{~m} \mathrm{~s}^{-1}\left(0 \div 1 \mathrm{~m} \mathrm{~s}^{-1}\right) 4 \%>1 \mathrm{~m} \mathrm{~s}^{-1}$; a response time of $10 \mathrm{~ms}$.

The anemometer was connected to an LSI 6-input BabucM BSA020 multiple data acquisition device with a 5000-sample memory (32 Kb EEPROM), and the resulting data were then processed using a personal computer.

In addition, a metal structure replicating the shape of the tendone vineyard was built in order to evaluate the air speeds close to the canopy directly exposed to the spray during pesticide treatments (Figure 3). The frame consisted of $30 \times 30 \mathrm{~mm}$ stainless steel square tubing, onto which nineteen 0.9 m-long steel rods were fixed at intervals of $0.25 \mathrm{~m}$ (Figure 4 ). The sprayer was kept stationery while measurements were performed, so that the vertical plane passing through the frame was aligned with the plane of the fan. The anemometer was used to measure air speeds at the point where each rod was joined to the frame.

Table 1 reports the results of these measurements for both airflow rates $\left(A_{1}, A_{2}\right)$. The application volumes were kept comparable (approximately $350 \mathrm{~L} \mathrm{ha}^{-1}$ ) using Albuz ATR nozzles with different orifice diameters at different working pressures: brown $(1.0 \mathrm{~mm})$, yellow $(1.2$

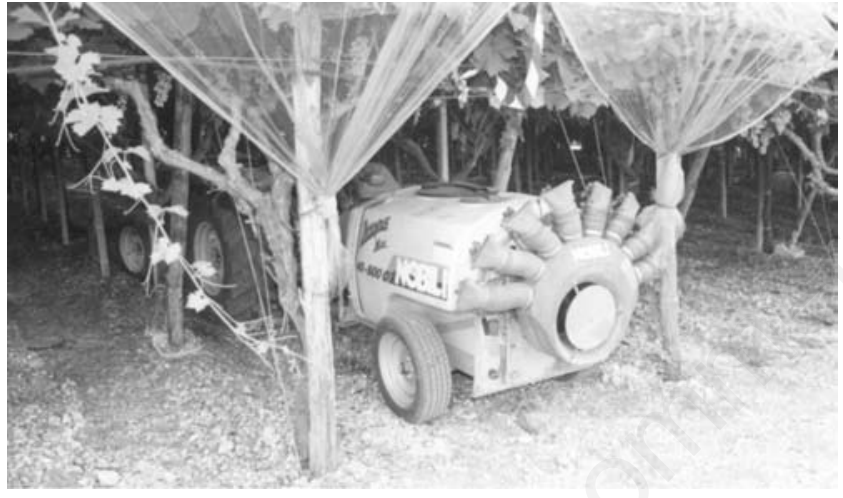

Figure 2. The sprayer under study. View of the stopper disc fitted on the air intake.

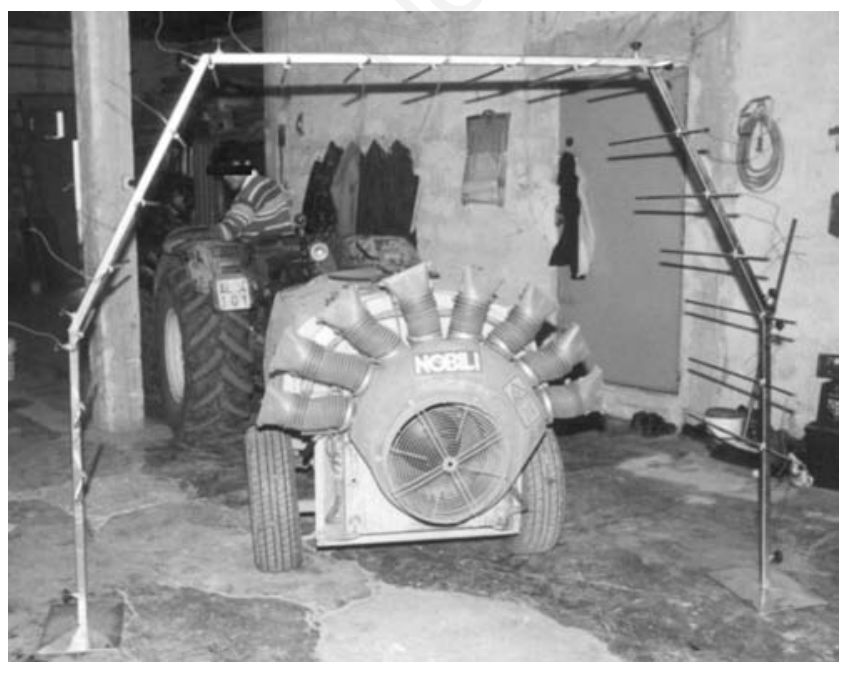

Figure 3. Equipment for evaluating the air speeds close to the canopy. $\mathrm{mm})$ and orange $(1.5 \mathrm{~mm})$. The application volumes $\mathrm{V}_{\mathrm{d}}$ were evaluated by collecting the liquid delivered through the nozzles during a working time of $60 \mathrm{~s}$; these were $352 \mathrm{~L} \mathrm{ha}^{-1}$ for the $1.0 \mathrm{~mm}$ nozzle, $354 \mathrm{~L} \mathrm{ha}^{-1}$ for the $1.2 \mathrm{~mm}$ nozzle, and $355 \mathrm{~L} \mathrm{ha}^{-1}$ for the $1.5 \mathrm{~mm}$ nozzle.

Table 2 summarises the experimental plan that was arranged according to a randomised block design with three replicates for each stage. Each replicate was performed with the sprayer using the $2+2$ nozzles, moving along three contiguous inter-rows and delivering a mixture containing a water-soluble food dye as a tracer (Tartrazine, Sigma Chemical: at $4 \mathrm{~g} \mathrm{~L}^{-1}$ ).

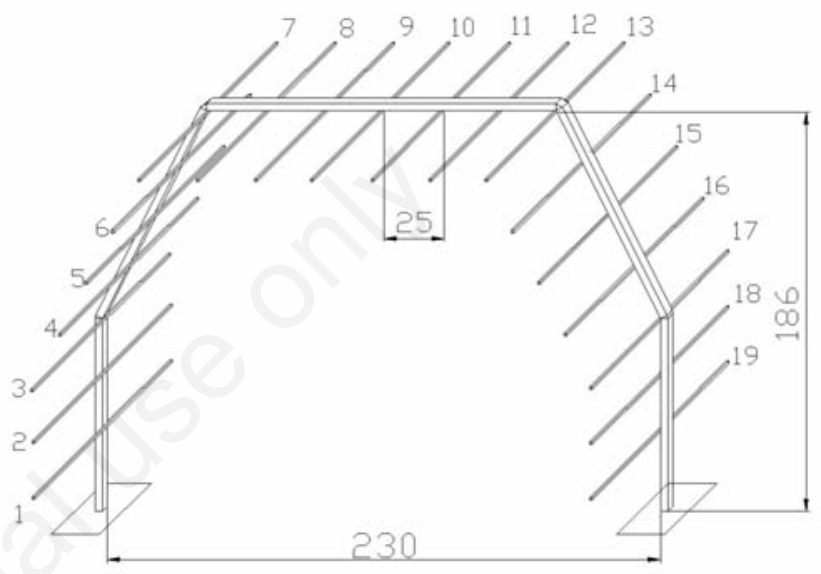

Figure 4. Structure for measuring air speeds $(\mathrm{cm})$.

Table 1. Measured air speeds $\left(\mathrm{m} \mathrm{s}^{-1}\right)$ for both airflow rates $\left(A_{1}, A_{2}\right)$

\begin{tabular}{|c|c|c|}
\hline Rod & A1 & A2 \\
\hline 1 & 0.61 & 0.39 \\
\hline 2 & 0.61 & 2.45 \\
\hline 3 & 2.45 & 9.82 \\
\hline 4 & 7 & 7.65 \\
\hline 5 & 7.15 & 6.56 \\
\hline 6 & 4.12 & 5.72 \\
\hline 7 & 3.8 & 3.72 \\
\hline 8 & 3.31 & 4.39 \\
\hline 9 & 4.85 & 5.32 \\
\hline 10 & 0.77 & 0.91 \\
\hline 11 & 0.85 & 0.78 \\
\hline 12 & 1.25 & 3.56 \\
\hline 13 & 3.74 & 4.22 \\
\hline 14 & 5.34 & 7.08 \\
\hline 15 & 6.01 & 4.95 \\
\hline 16 & 8.14 & 8.98 \\
\hline 17 & 1.64 & 3.43 \\
\hline 18 & 0.8 & 3.86 \\
\hline 19 & 0.34 & 1 \\
\hline Means $\mathrm{m} \mathrm{s}^{-1}$ & 3.30 & 4.46 \\
\hline
\end{tabular}


The sprayer was adjusted before each test according to the selected operational variables (forward speed, airflow rate, application volume). In addition, the trial used a patternator specially made for adjusting pesticide sprayers used in tendone vineyards (Guarella and Pascuzzi, 2000; Guarella and Pascuzzi, 2002). This patternator consisted of a horizontal, oblique and vertical metal profile, representing part of the tendone vineyard canopy, and including part of the vine trunk. The bearing structure consisted of 20x20x2 mm stainless steel square tubing fitted with fifteen interceptors. The interceptors were sets of thin steel sheets positioned in such a way as to maximise the surface area coming into contact with the wet airflow produced by the sprayer (Guarella and Pascuzzi, 2000; Guarella and Pascuzzi, 2002) (Figure 5).

The nozzles on each side of the sprayer were adjusted while the machinery was stationary, and the aim was to direct the working nozzles so as to obtain a cross-pattern of the spray consistent with the profile of the canopy. However, the outlet shape and sizes of the four contiguous diffusers containing the operative nozzles made it difficult to adjust the spray direction, so that it was impossible to adjust the crosspattern accurately. Therefore, the cross-pattern was adjusted for both stages by directing the switched-on nozzles to aim most of the spray towards those sectors of the tendone with greater leaf density ( $\alpha, \beta$ and $\delta, \varepsilon$ ) (Figure 5).

Spraying in the first stage took place between 9:30 and 17:30, when the average air temperature was $31^{\circ} \mathrm{C}$ : $\min =29^{\circ} \mathrm{C}, \max =32^{\circ} \mathrm{C}$, average HR $37 \%(\min =27 \%, \max =51 \%)$ and the average wind speed was $2.4 \mathrm{~m}$ $\mathrm{s}^{-1}\left(\min =1.3 \mathrm{~m} \mathrm{~s}^{-1}, \max =3.7 \mathrm{~m} \mathrm{~s}^{-1}\right)$.

In the second stage, spraying took place between 8:00 and 13:30, when the average air temperature was $28^{\circ} \mathrm{C}$ : $\min =25^{\circ} \mathrm{C}, \max =31^{\circ} \mathrm{C}$, average $\mathrm{HR} 58 \%(\min =46 \%, \max =73 \%)$ and the average wind speed was $1.2 \mathrm{~m} \mathrm{~s}^{-1}$ (min $=0.3 \mathrm{~m} \mathrm{~s}^{-1}$, $\left.\max =2.7 \mathrm{~m} \mathrm{~s}^{-1}\right)$.

\section{Morphological measurements}

In order to evaluate the penetration of the sprayed mixture, the canopy of the inter-row was arranged in five contiguous sectors (hereafter referred to as $\alpha, \beta, \chi, \delta, \varepsilon$ ), separated by the six horizontal lengthwise steel wires of the first grid (Figures 1 and 6).

In addition, the second grid subdivided the sectors into two levels (higher canopy level $\mathrm{L}_{\mathrm{h}}$, lower canopy level $\mathrm{L}_{\mathrm{l}}$ ), so that there were a total of 10 areas (Figure 6). On the day before the field tests, the following measurements were carried out on the canopy along the cross-section of the selected inter-rows of sprayer transit at the level of the vine trunks: minimum and maximum vegetation heights, canopy thickness, minimum and maximum height and width of the fruit-bearing area (second stage).

In addition, the leaf area index (LAI) was evaluated by picking all the leaves from 15 randomly chosen shoots. The surface $\left(\mathrm{S}_{\mathrm{i}}\right)$ and the mass $\left(\mathrm{M}_{\mathrm{i}}\right)$ of each sampled leaf were measured in the laboratory using a computerised image analysis system: a digital camera (Nikon D60 with 10.75 Mpixel), measuring software (Image Pro Plus, Media
Cybernetics), and a precision balance. This made it possible to calculate the following average ratio $\mathrm{r}_{\mathrm{av}}$, representative for the stage using the following formula:

$$
\mathrm{r}_{\mathrm{av}}=\frac{1}{\mathrm{n}} \cdot \sum_{\mathrm{i}=1}^{\mathrm{n}} \frac{\mathrm{S}_{\mathrm{i}}}{\mathrm{M}_{\mathrm{i}}}
$$

Therefore, for each sector of the canopy, all the leaves in a parallelepiped volume with a known ground surface $\left(\mathrm{S}_{0}\right)$ were picked and weighed $\left(\mathrm{M}_{0}\right)$, and the LAI was evaluated using the following formula:

$$
\mathrm{LAI}=\frac{\mathrm{r}_{\mathrm{av}} \cdot \mathrm{M}_{0}}{\mathrm{~S}_{0}}
$$

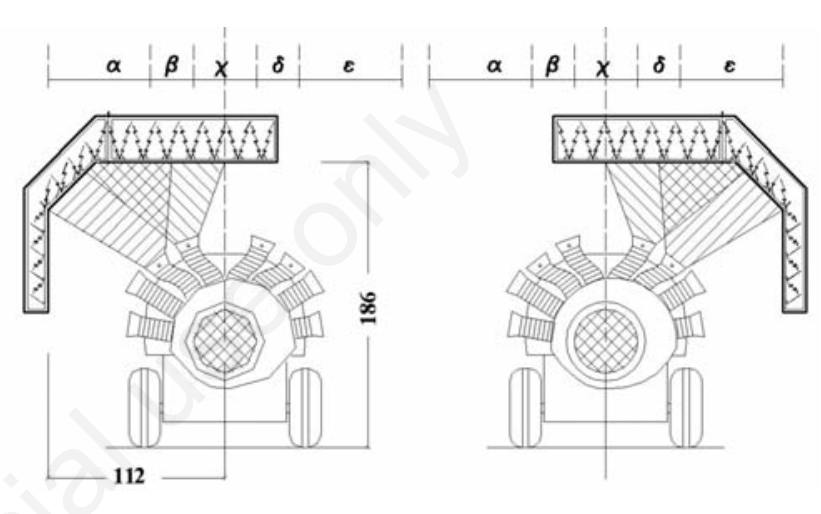

Figure 5. Adjustment of the cross-pattern produced by each side of the sprayer using the patternator $(\mathrm{cm})$.

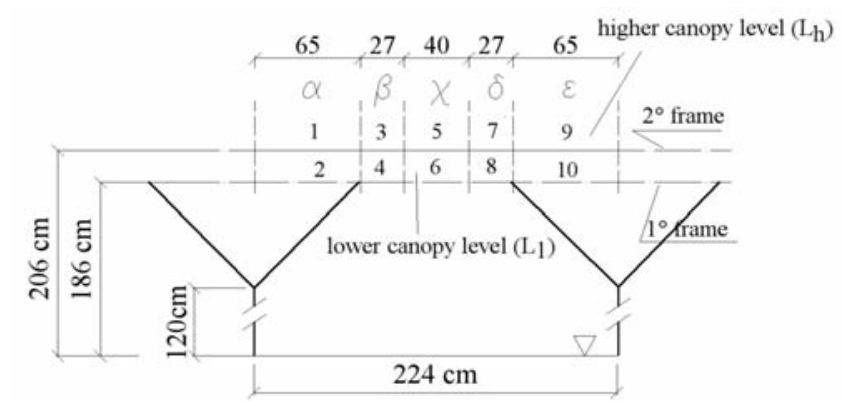

Figure 6. Canopy arrangement in the inter-row $(\mathrm{cm})$. Sectors $(\alpha$, $\beta, X, \delta, \varepsilon)$, and levels $\left(\mathbf{L}_{h}, L_{l}\right)$.

\begin{tabular}{|c|c|c|c|c|c|c|}
\hline Combination & $\begin{array}{l}\text { Air flow rate } \\
\mathrm{m}^{3} \mathrm{~s}^{-1}\end{array}$ & $\begin{array}{l}\text { Forward speed } \\
\qquad \mathrm{m} \mathrm{s}^{-1}\end{array}$ & $\begin{array}{l}\text { Nozzle diameter } \\
\text { mm }\end{array}$ & $\begin{array}{l}\text { Pressure } \\
\mathrm{MPa}\end{array}$ & $\begin{array}{l}\text { Flow rate } \\
\mu \mathrm{L} \text { min }^{-1}\end{array}$ & 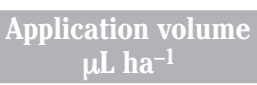 \\
\hline $\mathrm{A}_{1} v_{1}$ & 1.68 & 0.67 & 1.0 & 1.5 & 3.24 & 352 \\
\hline $\mathrm{A}_{1} v_{2}$ & 1.68 & 1.08 & 1.2 & 1.6 & 5.16 & 354 \\
\hline $\mathrm{A}_{1} v_{3}$ & 1.68 & 1.58 & 1.5 & 1.9 & 7.56 & 355 \\
\hline $\mathrm{A}_{2} v_{1}$ & 2.73 & 0.67 & 1.0 & 1.5 & 3.24 & 352 \\
\hline $\mathrm{A}_{2} v_{2}$ & 2.73 & 1.08 & 1.2 & 1.6 & 5.16 & 354 \\
\hline $\mathrm{A}_{2} v_{3}$ & 2.73 & 1.58 & 1.5 & 1.9 & 7.56 & 355 \\
\hline
\end{tabular}

Table 2. Experimental plan carried out. 


\section{Leaf sampling and data analysis}

After each replicate, 40 leaves were picked from the canopy in the middle of the sprayed plot and placed in individually labelled plastic bags. The number of leaves detached from each sector and level is reported in Table 3 , according to the size of the sectors. For the experimental plan of each phenological stage, 720 leaves were collected in order to evaluate spray deposition and its penetration into the canopy. The unitary deposit on each leaf $d_{l}\left(\mu \mathrm{L} \mathrm{cm}^{-2}\right)$ was estimated using a spectrophotometric technique (Cerruto, 2007b). All deposits were then normalised $d_{n}\left(\mu \mathrm{L} \mathrm{cm}^{-2}\right)$ to a fixed application volume $V_{N}$ of $350 \mathrm{~L} / \mathrm{ha}$, so as to account for the differences in the $V_{d}$ delivered application volumes (Cerruto, 2007b) using the following formula:

$$
\mathrm{d}_{\mathrm{n}}=\mathrm{d}_{1} \cdot \frac{\mathrm{V}_{\mathrm{N}}}{\mathrm{V}_{\mathrm{d}}}
$$

\section{Statistical analysis}

The normalised unitary deposits $d_{n}$ were statistically analysed by applying the analysis of variance (ANOVA) separately for each stage. ANOVA was carried out according to a split-plot scheme, considering two main plot factors (airflow rate and forward speed) and two sub-plot factors (sector and canopy level). Mean separation was performed according to Tukey's test. $\mathrm{P}<0.05$ was considered significant.

\section{Results and discussion}

\section{Morphological measurements of the tendone vineyard}

The anti-hail net, whatever the phenological stage and green pruning operations carried out, influenced the upper outline of the canopy. On the contrary, green pruning (defoliation, secondary shoots thinning) conditioned the lower outline of the canopy and, therefore, its thickness. Green pruning was carried out from the appearance of the grape clusters, and aimed to eliminate nearly all leaves and non-fruit-bearing shoots from the lower canopy level $\left(\mathrm{L}_{\mathrm{l}}\right)$. Figure 7 shows the average profiles of the canopy measured during the two stages. Along the cross- section of the interrows, the canopy was thickest at the level of the grapevine trunks and thickness decreased at the centre lines; this spatial distribution of the canopy was obviously due to the type of pruning, with the fruit-bearing shoots aligned in parallel (Figure 1). In the berry touch stage, leaf density was greater and there were two fruit-bearing areas (Figure 7).

LAI variability along the cross-section of the inter-row was also affected by the winter pruning system used, especially by the parallel alignment of the fruit-bearing shoots. Furthermore, it should be added that peak LAI values were observed at the points where the fruit-bearing shoots were attached to the steel wires, and not at the level of the grapevine trunks where the greatest canopy thickness was recorded (Table 4).

\section{Foliar deposition in the end of flowering stage}

In order to normalise the residual distribution and make the variances homogeneous, raw data were transformed according to the following power relation:

$$
\mathrm{d}_{\mathrm{nt}}=\mathrm{d}_{\mathrm{n}}^{0.4}
$$

Table 5 shows the main results of ANOVA applied to the transformed data. It shows that neither the forward speed, nor the airflow rate, nor their interaction, significantly influenced foliar deposition. Significant differences were observed between the five sectors, as well as between the two levels and in the interaction airflow rate $\mathrm{x}$ level.

Tukey's test (Figure 8) was applied to evaluate any difference between the values registered on the five sectors, and shows that the normalised unitary deposits on Sectors $\alpha$ and $\varepsilon$ were comparable ("a" in Figure 8), but that they differed significantly from the foliar deposition evaluated on Sector $\beta$ ("b" in Figure 8); furthermore there were significant differences between deposits on Sectors $\alpha, \varepsilon$ and $\beta$ and the

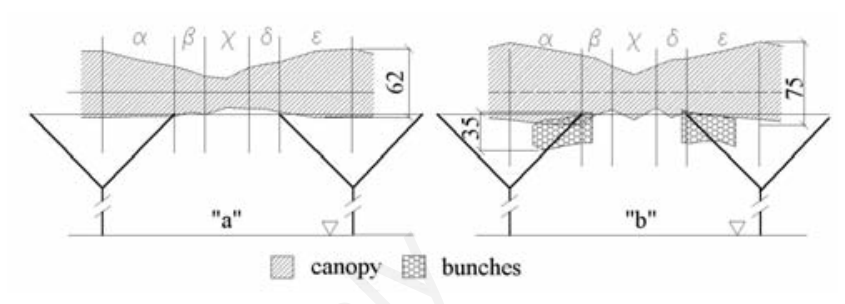

Figure 7. Average profiles of canopy and fruit-bearing areas (cm). "a" end of flowering stage; "b" berry touch stage.

Table 3. Leaves detached from each sector and level.

\begin{tabular}{lccccc} 
& \multicolumn{5}{c}{ Sectors } \\
Levels & $\alpha$ & $\beta$ & $\chi$ & $\delta$ & $\varepsilon$ \\
$\mathrm{L}_{\mathrm{h}}$ & 5 & 3 & 4 & 3 & 5 \\
$\mathrm{~L}_{\mathrm{l}}$ & 5 & 3 & 4 & 3 & 5 \\
\hline
\end{tabular}

Table 4. Leaf area index evaluation for both the stages under study.

\begin{tabular}{lccccc} 
& \multicolumn{5}{c}{ Sectors } \\
Levels & $\alpha$ & $\boldsymbol{\beta}$ & $\boldsymbol{\chi}$ & $\delta$ & $\varepsilon$ \\
End of flowering & 4.19 & 4.41 & 1.99 & 3.89 & 3.57 \\
Berry touch & 5.50 & 6.09 & 3.66 & 7.71 & 5.46 \\
\hline
\end{tabular}

\begin{tabular}{|c|c|c|}
\hline Source & $\begin{array}{l}\text { End of flowering } \\
\qquad P \\
\text { analysis }\end{array}$ & $\begin{array}{c}\text { Berry touch } \\
\text { P }\end{array}$ \\
\hline Forward speed $(v)$ & $0.200 \mathrm{~ns}$ & $0.005^{* *}$ \\
\hline Airflow rate (A) & $0.591 \mathrm{~ns}$ & $0.086 \mathrm{~ns}$ \\
\hline$v \times A$ & $0.517 \mathrm{~ns}$ & $0.089 \mathrm{~ns}$ \\
\hline \multicolumn{3}{|c|}{ Sub-plot analysis } \\
\hline Sector (S) & $0.000^{* * *}$ & $0.000^{* * *}$ \\
\hline Level (L) & $0.000^{* * *}$ & $0.000^{* * *}$ \\
\hline $\mathrm{AxL}$ & $0.006^{* *}$ & $0.001^{* *}$ \\
\hline $\mathrm{L}\left(\mathrm{A}_{1}\right)$ & $0.000^{* * *}$ & $0.000^{* * *}$ \\
\hline $\mathrm{L}\left(\mathrm{A}_{2}\right)$ & $0.000^{* * *}$ & $0.000^{* * *}$ \\
\hline
\end{tabular}

Table 5. Main results of the ANOVA of the normalised deposits. 
deposits registered on Sectors $\chi$ and $\delta$ ("c" in Figure 8). Therefore, foliar deposition in Sectors $\alpha\left(0.455 \mu \mathrm{L} \mathrm{cm}^{-2}\right)$ and $\varepsilon\left(0.461 \mu \mathrm{L} \mathrm{cm}^{-2}\right)$ was approximately 2.0 times that in Sectors $\chi\left(0.243 \mu \mathrm{L} \mathrm{cm}^{-2}\right)$ and $\delta$ $\left(0.299 \mu \mathrm{L} \mathrm{cm}^{-2}\right)$, and approximately 1.4 times that in Sector $\beta(0.331$ $\mu \mathrm{Lcm}^{-2}$ ). This large difference between Sectors $\alpha$ and $\varepsilon$ on the one hand, and Sectors $\beta, \chi$ and $\delta$ on the other, may have been caused by the adjustment made to the sprayer cross-pattern. On the other hand, there are substantial differences between the air speeds measured from Rod no. 3 to Rod no. 17 (Table 1): from $0.77\left(\operatorname{Rod}\right.$ no. 10) to $8.14 \mathrm{~m} \mathrm{~s}^{-1}$ (Rod no. 16) with airflow rate $A_{1}$; from $0.78\left(\operatorname{Rod}\right.$ no. 11) to $9.82 \mathrm{~m} \mathrm{~s}^{-1}$ (Rod no. 5) with airflow rate $A_{2}$. In addition, for both airflow rates, the highest air speeds were measured at Rods 3-4-5-6-7 and 13-14-15-16-17, corresponding, respectively, to Sectors $\alpha$ and $\varepsilon$ which had the greatest deposits.

Tukey's test was used to estimate dissimilarities between levels and this indicates that the average deposit measured at the lower level $\mathrm{L}_{l}$ (letter "a" in Table 6) was significantly higher than the deposit measured at the higher canopy level $L_{h}$ (letter " $b$ " in Table 6): the ratio is approximately 2.6. This behaviour could be explained by the air speeds, which were very low in some points with both airflow rates (Rods 1011 ), and also by the sprayer airflow rates that were inadequate for this type of canopy. This inadequate airflow rate is confirmed by the factor level - analysed considering airflow rates [ $\mathrm{L}\left(\mathrm{A}_{1}\right)$ and $\mathrm{L}\left(\mathrm{A}_{2}\right)$ in Table 5] individually - which influenced foliar deposition. In this case, the resultant Tukey's test shows significant differences between the foliar deposition registered on the two levels ("a" and "b" in Table 6) for both airflow rates: the average deposit measured on the lower canopy level with $A_{1}$ is approximately 3 times the average deposit on the higher canopy level, and is approximately 2.3 times this with air flow rate $\mathrm{A}_{2}$. In fact, as seen in Table 6 , the higher airflow rate $\mathrm{A}_{2}$, which allowed higher air speeds (Table 1), produced a greater average deposit in the higher canopy level than $A_{1}$. Therefore, the increased airflow rate caused a reduction in the average deposit on the lower canopy level and an increase in the average deposit on the higher canopy level.

\section{Foliar deposition in the berry touch stage}

The overall mean deposit (grand mean) was lower than that of the first stage $(0.401 \mu \mathrm{L} \mathrm{cm})^{-2}$ vs $\left.0.442 \mu \mathrm{L} \mathrm{cm}^{-2}\right)$; the application volumes in the two stages were comparable. Therefore, this result is due to the $57 \%$ increase in the LAI and to the shielding effect of the grape clusters. Once again, the power transformation of the raw data was necessary in order to normalise the frequency distribution and equalise the variances:

$$
\mathrm{d}_{\mathrm{nt}}=\mathrm{d}_{\mathrm{n}}^{0.3}
$$

Table 5 shows the main results of ANOVA applied to the transformed data. Unlike the conclusions drawn for the first stage, the main plot analysis shows the influence of the forward speed on foliar deposition. In the first stage, the sub-plot analysis highlights significant differences between sectors as well as between levels, and in the interaction airflow rate x level (Table 5).

Specifically, Tukey's test (Figure 9), used to evaluate differences between the forward speeds, indicates that the average deposits produced with $v_{1}\left(0.252 \mu \mathrm{L} \mathrm{cm}^{-2}\right)$ and $v_{2}\left(0.257 \mu \mathrm{L} \mathrm{cm}^{-2}\right)$ were comparable to each other ("a" in Figure 9), and significantly lower than the foliar deposition evaluated with forward speed $v_{3}\left(0.164 \mu \mathrm{L} \mathrm{cm}{ }^{-2}\right)$ ("b" in Figure 9). At this stage, the highest speed produced the poorest penetration of the spray into the canopy, with the lowest foliar deposition in the higher level: about $10 \%$ of the deposition measured in the corresponding lower canopy level. It is probable that the highest forward
Table 6. Tukey's test between levels.

\begin{tabular}{cccc} 
& & Find of flowering & Berry touch \\
Level & $\mathrm{L}_{\mathrm{h}}$ & $0.205^{\mathrm{b}}$ & $0.064^{\mathrm{b}}$ \\
& $\mathrm{L}_{\mathrm{l}}$ & $0.550^{\mathrm{a}}$ & $0.544^{\mathrm{a}}$ \\
$\mathrm{L}\left(\mathrm{A}_{1}\right)$ & $\mathrm{L}_{\mathrm{h}}$ & $0.198^{\mathrm{b}}$ & $0.048^{\mathrm{b}}$ \\
& $\mathrm{L}_{\mathrm{l}}$ & $0.603^{\mathrm{a}}$ & $0.563^{\mathrm{a}}$ \\
\hline $\mathrm{L}\left(\mathrm{A}_{2}\right)$ & $\mathrm{L}_{\mathrm{h}}$ & $0.212^{\mathrm{b}}$ & $0.085^{\mathrm{b}}$ \\
& $\mathrm{L}_{l}$ & $0.500^{\mathrm{a}}$ & $0.527^{\mathrm{a}}$ \\
\hline
\end{tabular}

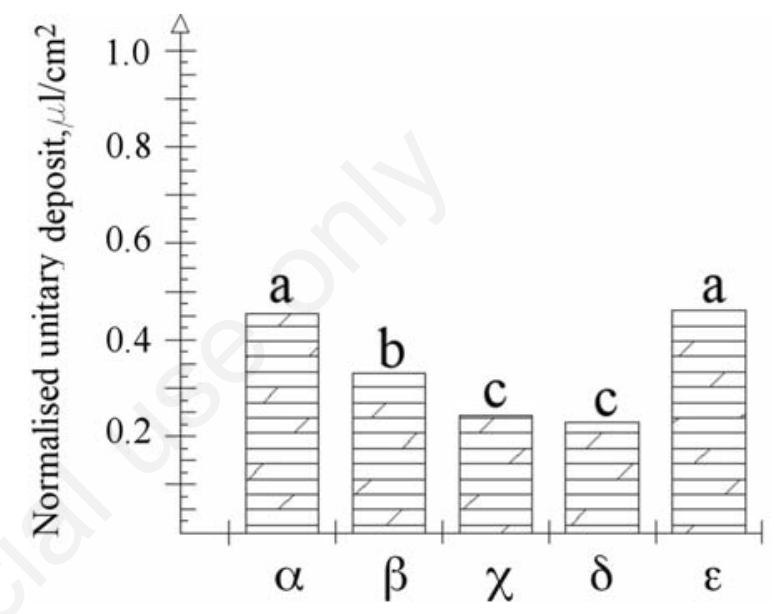

Figure 8. The end of flowering stage (Tukey's test between sectors).

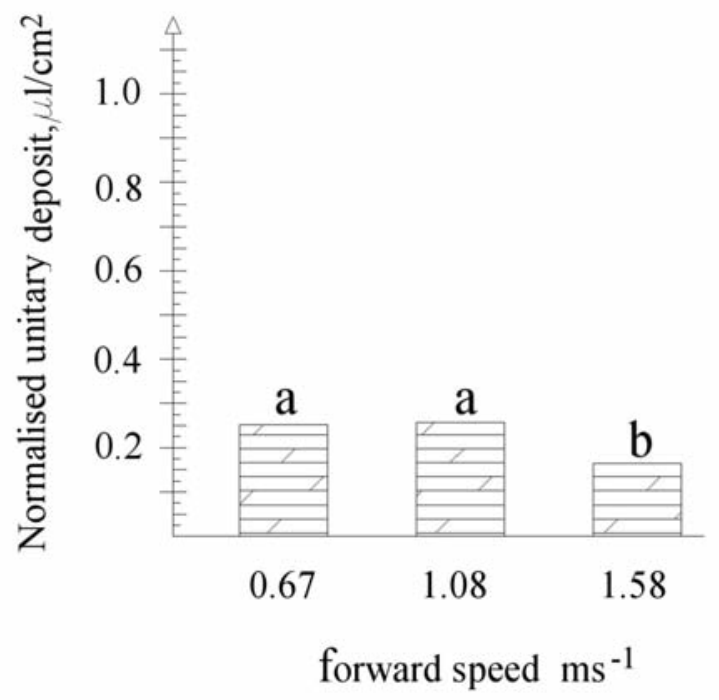

Figure 9. The berry touch stage (Tukey's test between forward speeds). 
speed $v_{3}$ increased the effect created by the lack of a suitable airflow in a context with higher leaf density.

Tukey's test indicates that the deposits on Sectors $\alpha$ and $\varepsilon$ were comparable ("a" in Figure 10), and were significantly different from the deposits measured on Sectors $\beta, \chi$ and $\delta$ ("b" in Figure 10). The foliar deposits in Sectors $\alpha\left(0.363 \mu \mathrm{L} \mathrm{cm}^{-2}\right)$ and $\varepsilon\left(0.357 \mu \mathrm{L} \mathrm{cm}{ }^{-2}\right)$ were approximately 3.0 times that in Sectors $\beta\left(0.134 \mu \mathrm{L} \mathrm{cm}^{-2}\right), \chi(0.124 \mu \mathrm{L}$ $\left.\mathrm{cm}^{-2}\right)$ and $\delta\left(0.119 \mu \mathrm{L} \mathrm{cm}^{-2}\right)$.

This appreciable difference between the external $(\alpha, \varepsilon)$ and the internal $(\beta, \chi, \delta)$ sectors may be explained by the increased LAI and the presence of grape clusters impeding spray penetration. As mentioned above, it was impossible to obtain a uniform canopy coverage because of: i) the poor calibration of the sprayer, carried out only by directing the four diffusers closer to the median plane of the machine towards the sectors with higher leaf density ( $\alpha, \beta$ and $\delta, \varepsilon)$; and ii) the dramatic differences in the air speeds at the canopy level (Table 1).

Once again, the average deposit measured at the lower level $\mathrm{L}_{l}$ ("a" in Table 6) was significantly higher than the deposit measured at the higher canopy level $\mathrm{L}_{h}$ ("b" in Table 6): their ratio is approximately 8.50. In addition, the factor level was analysed by considering the airflow rates [ $\mathrm{L}\left(\mathrm{A}_{1}\right)$ and $\mathrm{L}\left(\mathrm{A}_{2}\right)$ in Table 5] individually, and influenced the foliar deposition. The resultant Tukey's test shows significant differences in the foliar deposition registered on the two levels ("a" and " $b$ " in Table 6, respectively) for both airflow rates. The ratio between the deposits measured at the two canopy levels is approximately 12 with airflow rate $A_{1}$, and approximately 6 with airflow rate $A_{2}$. These values highlight the increased difficulty in reaching the higher canopy level. It is probable that the ratio obtained with $\mathrm{A}_{2}$ is lower because this airflow rate allowed the spray to penetrate into the vegetation more efficiently, and it also produced greater turbulence near the canopy. The turbulence might also explain the increase in spray deposit at the lower level $\left(0.527 \mu \mathrm{L} \mathrm{cm}^{-2}\right)$ compared with the corresponding deposit in the first stage $\left(0.500 \mu \mathrm{L} \mathrm{cm}^{-2}\right)$, even if some of the spray was intercepted by the grape clusters.

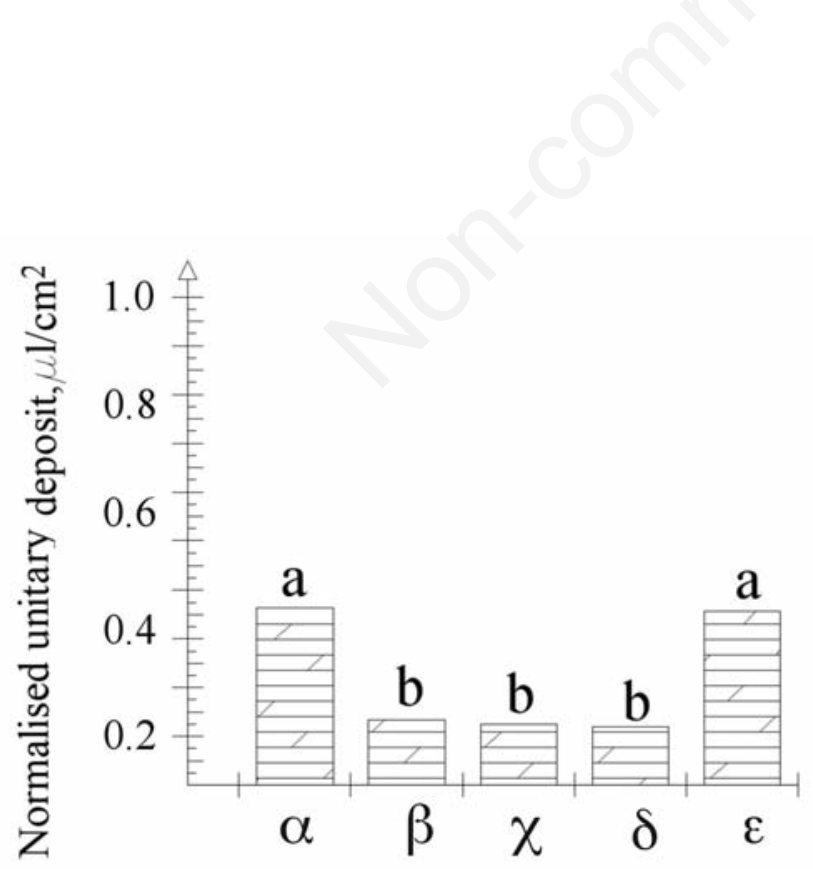

Figure 10. The berry touch stage (Tukey's test between sectors).

\section{Conclusions}

Although further experimental tests are required for a better assessment of the performance of the sprayer under investigation, the results obtained in this trial allow some reflections to be made concerning this machine and its use in tendone vineyards. The forward speeds, evaluated in the range $0.67-1.58 \mathrm{~m} \mathrm{~s}^{-1}$, did not significantly influence the mean foliar deposition in the end of flowering stage. On the contrary, the highest speed in the berry touch stage (full foliage development) differed significantly from the other two speeds examined and produced the lowest foliar deposition and the worst penetration of the spray in the higher level of the canopy. According to this result, increased forward speed during the early growth stages is beneficial because it ensures a more rapid intervention with no effect on foliar deposition.

The airflow rates in the range $1.68-2.73 \mathrm{~m}^{3} \mathrm{~s}^{-1}$ did not significantly influence the mean foliar deposition in the two stages evaluated. The increased airflow rate caused a reduction in the average deposit in the lower canopy level and an increase in the average deposit in the higher canopy level. This suggests the use of low airflow rates during the early growth stages would reduce power consumption. The results concerning both forward speed and airflow rate agree with previous findings (see Introduction section) and more specifically with the results obtained by Cerruto for the same vineyard training system.

The air speeds produced by the fan were measured at several points near the canopy, and show a very changeable trend, with fluctuating values in the range $0.77-8.14 \mathrm{~m} \mathrm{~s}^{-1}$ (average value $3.30 \mathrm{~m} \mathrm{~s}^{-1}$ ) for the lower airflow rate $A_{1}=1.68 \mathrm{~m}^{3} \mathrm{~s}^{-1}$ and $0.78-9.82 \mathrm{~m} \mathrm{~s}^{-1}$ (average value $4.46 \mathrm{~m} \mathrm{~s}^{-1}$ ) for the higher airflow rate $\mathrm{A}_{2}=2.73 \mathrm{~m}^{3} \mathrm{~s}^{-1}$. The lowest values with both airflows were registered at the Sector $\chi$ level. These highly variable values did not allow a uniform distribution of the spray in the canopy and were too low to ensure good penetration of the jet into the canopy, especially in the second stage of growth when the foliage was denser. In both stages, and particularly the second stage, there were significant differences between the foliar deposition registered on the two levels for both airflow rates, with a high ratio between the average deposit at the lower canopy level and the average deposit at the higher canopy level.

It was not possible to achieve a cross-pattern of spray consistent with the profile of the canopy due to the low air speeds, and also to the limited possibility of changing the orientation of the four contiguous diffusers containing the operative nozzles. In both stages of growth, adjustment of the cross-pattern by directing the diffusers towards the sectors of the tendone with higher leaf density produced significant differences between the deposits registered on Sectors $\alpha$ and $\varepsilon$ and the deposits on the other sectors $(\beta, \chi, \delta)$; foliar deposition in Sectors $\alpha$ and $\varepsilon$, was always greater than in Sectors $\beta, \chi$ and $\delta$.

Finally, the trial sprayer did not produce a higher airflow rate than the standard air-assisted vineyard sprayers on the market (ranging from 5 to $9 \mathrm{~m}^{3} \mathrm{~s}^{-1}$ ), and this meant that it was not effective for the dense canopy typical of tendone vineyards. In table grape vineyards, however, the main objective of pesticide treatments is to protect the grapes clusters, and poor PPP deposition on top of the canopy is irrelevant. In any case, the use of standard air-assisted sprayers in these vineyards does not ensure sufficient deposition on top of the canopy, especially in the later stages of growth. Therefore, if the purpose of spraying is only to protect grape clusters, the trial sprayer may be regarded as being suitable for use in this kind of vineyard. 


\section{References}

Balsari P., Tamagnone M. 1998. The necessity of determine the correct amount of air to use in airblast sprayer. Proc. AGENG98, 24-27 August, Oslo, Norway. CD-ROM.

Balsari P., Oggero G., Marucco P. 2007. Proposal of a guide for sprayers calibration. Second European Workshop on Standardised Procedure for the Inspection of Sprayers in Europe, Straelen, Germany, pp 60-73.

Cerruto E. 2007a. Further studies on the variation of spray deposits in vineyards with airflow rate. J. Agric. Eng. 1:71-8.

Cerruto E. 2007b. Influence of airflow rate and forward speed on the spray deposit in vineyards. J. Agric. Eng. 1:7-14.

Cerruto E., Emma G., Manetto G. 2008. Study of a new model of sprayer for applications in "tendone" vineyards. J. Agric. Eng. 1:41-8.

Cross J.V., Walklate P.J., Murray R.A., Richardson G.M. 2001a. Spray deposits and losses in different sized apple trees from an axial fan orchard sprayer: 1. Effects of spray liquid flow rate. Crop Prot. 20:13-30.

Cross J.V., Walklate P.J., Murray R.A., Richardson G.M. 2001b. Spray deposits and losses in different sized apple trees from an axial fan orchard sprayer: 2. Effects of spray quality. Crop Prot. 20:333-43.

Cross J.V., Walklate P.J., Murray R.A., Richardson G.M. 2003. Spray deposits and losses in different sized apple trees from an axial fan orchard sprayer: 3. Effects of air volumetric flow rate. Crop Prot. 22:381-94.

Eichhorn K.W. 1984. Entwicklung der Blattfläche der Rebe. Der Deutsche Weinbau 36:1532-7.

ENAMA (Italian Body for Agricultural Mechanization). 1996. Procedures for evaluating the operative characteristics and safety of agricultural machines. Available from: http://www.enama.it

Guarella P., Pascuzzi S. 2000. Test bench for calibration of spraying machines used in "tendone" trained vines. Design and operation aspects. Riv. Ing. Agr. 1:18-23.

Guarella P., Pascuzzi S. 2002. Computer-aided measurement system for checking and calibrating pesticide spraying machines. Riv. Ing. Agr. 4:1-8.

IS0 (International Organization for Standardization). 2000. Equipment for crop protection - test methods for air-assisted sprayers for bush and tree crops. IS0 9898:2000. Geneva: International Organization for Standardization Publications; 2000. Available from: http://www.iso.org/iso/catalogue_detail.htm?csnumber=17781

ISTAT (Italian Central Statistics Institute). 2012. Table C26 - Area (hectares) and production (quintals): table grapes, wine grapes, wine. Data by Province - Year 2012. Available from: http://agri. istat.it/jsp/dawinci.jsp?q=plC260000030000173200\&an=2012\&ig= $1 \& \mathrm{ct}=604 \& \mathrm{id}=21 \mathrm{~A} \% 7 \mathrm{C} 15 \mathrm{~A} \% 7 \mathrm{C} 73 \mathrm{~A}$

Pergher G., Gubiani R. 1995. The effect of spray application rate and airflow rate on foliar deposition in a hedgerow vineyard. J. Agric. Eng. Res. 61:205-16.

Pergher G. 2006. The effect of airflow rate and forward speed on spray deposition from a vineyard sprayer. J. Agric. Eng. 1:17-23.

Pezzi F., Rondelli V. 2000. The performance of an air-assisted sprayer operating in vines. J. Agric. Eng. Res. 76:331-40.

Planas S., Solanelles F., Fillat A., Walklate P., Miralles A., Ade G., Pezzi F., Val L., Andersen P.G. 1998. Advances on air-assisted spraying on the Mediterranean orchards (fruit, vine and citrus). Proc. AGENG98, 24-27 August 1998, Oslo, Norway. CD-ROM.

Salyani M., Withney J.D. 1990. Ground speed effect on spray deposition inside citrus trees. Trans. ASAE 33:361-6.

Salyani M., Farooq M. 2003. Effect of sprayer airflow on spray within tree canopy. Proc. VII Workshop on Spray Application Techniques in Fruit Growing, 25-27 June, Cuneo, Italy, pp 227-235.

Salyani M., Serdynski J.W. 1993. A device and method for sprayer calibration. Appl. Eng. Agric. 9:29-32.

Vieri M. 2003. Spray airjet characterisation by impulse measurement. Proc. VII Workshop on Spray Application Techniques in Fruit Growing, 25-27 June, Cuneo, Italy, pp 149-156.

Wachowiak M., Kierzek R. 2009. Economic aspects of application of plant protection techniques. Prog. Plant Prot. 49:1668-75. 